\title{
Control of angiogenesis and host response by modulating the cell adhesion properties of an Elastin-Like Recombinamer-based hydrogel
}

${ }^{1}$ Sebastian Staubli*, ${ }^{1}$ Giulia Cerino*, ${ }^{2,3}$ Israel Gonzalez De Torre, ${ }^{2}$ Matilde Alonso

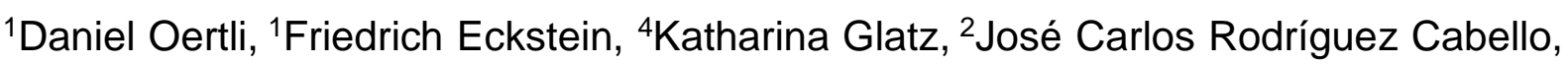
${ }^{1}$ Anna Marsano

1Department of Surgery, University Hospital Basel and Department of Biomedicine, University Basel, Switzerland

${ }^{2}$ G.I.R. BIOFORGE, Universidad de Valladolid, CIBER-BBN Edificio LUCIA, Paseo de Belen 19, Valladolid, Spain

${ }^{3}$ Technical Proteins NanoBiotechnology S.L., Edificio CTTA, Paseo Belén 9A, 47011, Valladolid, Spain

${ }^{4}$ Institute of Pathology, University Hospital Basel, University of Basel Switzerland

${ }^{*}$ Equally contributing authors

Corresponding authors:

Anna Marsano, PhD

Cardiac Surgery and Engineering Group, Departments of Biomedicine and Surgery, University of Basel, University Hospital Basel, Hebelstrasse 20, 4031, Basel, CH.

Phone: +41 (0)6132 87448

Fax: +41612653990

Email: Anna.Marsano@usb.ch

José Carlos Rodríguez Cabello, PhD

G.I.R. BIOFORGE, Universidad de Valladolid, Edificio LUCIA, Paseo de Belen 19, Valladolid, Spain

Phone: +34 983184686

Email: roca@bioforge.uva.es 


\section{Abstract}

The control of the in vivo vascularization of engineered tissue substitutes is essential in order to obtain either a rapid induction or a complete inhibition of the process (e.g. in muscles and hyaline-cartilage, respectively). Among the several polymers available, Elastin-Like Recombinamers (ELRs)-based hydrogel stands out as a promising material for tissue engineering thanks to its viscoelastic properties, non-toxicity, and non-immunogenicity. In this study, we aimed to modulate the high angiogenic potential of adipose tissue-derived stromal vascular fraction (SVF) cells, predominantly composed of endothelial/mural and mesenchymal cells, by simply varying the cell adhesion properties of ELRs-hydrogels. Human SVF cells, embedded in RGD-REDVbioactivated or unmodified ELRs-hydrogels, were implanted in rat subcutaneous pockets either immediately or upon 5-day-culture in perfusion- bioreactors. Perfusionbased culture enhanced the endothelial cell cord-like-organization and the release of pro-angiogenic factors in functionalized constructs. While in vivo vascularization and host cell infiltration within the bioactivated gels were highly enhanced, the two processes were strongly inhibited in non-functionalized hydrogels up to 28 days. ELRsbased hydrogels showed a great potential to determine the successful integration of engineered substitutes thanks to their capacity to finely control the angiogenic/inflammation process at the recipient site, even in presence of SVF cells.

Keywords: elastin-like recombinamers, functionalization, stromal vascular fraction, angiogenesis, host reaction. 


\section{Introduction}

The in vitro generation of functional living engineered tissue substitutes (e.g. cartilage, myocardium) [1-2] has significantly progressed in the past years starting by choosing a suitable biomaterial and competent cell source. Nevertheless, it is essential to control the process of angiogenesis and host response at the recipient site to ensure the functionality and survival of the engineered graft [3, 4]. In this regard, many aspects need to be controlled according to specific purposes. For instance, the material degradation-rate needs to fit the envisioned application, allowing the desired ingrowth of host cells and extracellular matrix deposition (ECM) [3]. Furthermore, the prompt in vivo induction of angiogenesis is often mandatory (e.g. myocardium) [5], whereas other tissues retain their function upon implantation only if their avascular nature is preserved in healthy condition (e.g. hyaline cartilage, cardiac valve substitute) [6-8]. Biomaterials alone could block or promote angiogenesis via functionalization, architecture, or composition [9]. Synthetic or natural, inert or bioactive polymers can indeed be used not only to merely provide mechanical support but also to induce regeneration in the damaged tissues [10]. Therefore, when generating an engineered substitute, the selection of the biomaterial is crucial as it needs to fit with the targeted tissue and it has to be able to modulate the in vivo angiogenesis and the host interaction at the recipient site.

To induce angiogenesis, the delivery of relevant pro-angiogenic factors $[5,11]$ as well as of progenitor or mature endothelial cells is often used [5]. Mesenchymal stromal cells have been largely used in many clinical applications for regenerative/repair purposes, thanks to their capability to release a broad range of factors (e.g. proangiogenic, anti-inflammatory) [12-13] and to differentiate into functional cells (e.g. chondrocyte or osteocytes, cardiomyocyte) [14-19]. In this study, we rely on the 
adipose tissue-derived stromal vascular fraction (SVF), which is known to be inherently composed of a heterogeneous cell population, consisting of the key cell types (as mesenchymal and endothelial/mural progenitor cells), capable of driving important paracrine-mediated cellular processes (e.g. angiogenesis, inflammation) [20-22].

The use of bioactive or inert hydrogel to deliver cells might totally change their paracrine effects and capability to directly interact with the host tissue. Among the recently developed hydrogels, those based on Elastin-Like Recombinamers (ELRs) stand out for their non-toxicity, non-immunogenicity, mechanical stiffness in the range of 1-10 $\mathrm{kPa}$ [23], and the functionalization possibility [24], offering a versatile celldelivery platform for multiple tissue regeneration purposes. Moreover, the elastin integration in engineered tissues (e.g. heart valves, myocardium, skin, hyaline cartilage) is relevant for their regeneration, since it is one of the key ECM components and its production usually decreases during adulthood [25]. In this work, we focus on investigating how the ELR-based hydrogels, in their inert or bioactivated form, could modulate the in vitro and in vivo angiogenic potential of human SVF cells. In particular, we hypothesized that the ELRs bioactivation, through the inclusion of functional RGD and REDV sequences, would promote cell adhesion and enhance the SVF response in terms of in vitro angiogenic factor release and endothelial cell organization, also improving the in vivo angiogenic potential and integration with the host tissue.

In addition, since it has been demonstrated that perfusion-based 3D culture ensured the reproducible generation of functional engineered tissues of several millimeters of thickness [26] and promoted the in vitro prevascularization [27], we also aimed to compare the effects of the dynamic culture on the formation of endothelial cord-like structures compared to static condition. 


\section{Materials and Methods}

\section{3D perfusion culture of cell-based ELR constructs}

\subsection{Stromal Vascular Fraction Cell Isolation}

Subcutaneous abdominal adipose tissue in form of liposuction was obtained from three healthy donors undergoing plastic surgery after patient informed consent in accordance with a protocol approved by the Ethical Committee of Basel University Hospital.

Adipose tissue was minced and digested with 0.075\% type II collagenase (355 U/mg, Worthington, USA) in phosphate buffered saline (PBS, Invitrogen) at $37^{\circ} \mathrm{C}$ for 60 minutes. After centrifugation at $1500 \mathrm{rpm}$ for 10 minutes, the floating lipid layer was discarded and the cell pellet was strained through a $100 \mu \mathrm{m}$ and then a $70 \mu \mathrm{m}$ nylonmesh to remove fibrous debris. Next the SVF cell pellet was resuspended in growth medium consisting of DMEM high glucose (Sigma-Aldrich), 10\% (v/v) Fetal Bovine Serum (FBS, HyClone), 1\% (v/v) penicillin/streptomycin, 1\% (v/v) glutamine, and 1\% (v/v) hepes. SVF cells were frozen in 10\% dimethyl sulfoxide (DMSO), $90 \%$ FBS medium and stored in liquid nitrogen.

\subsection{Preparation of ELR -based constructs}

The ELRs employed in this work were previously described and characterized [23; 29]. Briefly, all steps were carefully performed under sterile conditions. ELR (Technical Proteins Nanobiotechnology) VKV-Cyclo, VKV-N3, and RGD6 Ciclo and REDV-N3, carrying general cell adhesion sequences (Arg-Gly-Asp, RGD) or specific endothelial cell adhesion sequences (Arg-Glu-Asp-Val, REDV) were dissolved in $4^{\circ} \mathrm{C}$ PBS at a concentration of $50 \mathrm{mg} / \mathrm{ml}$ and kept at $4^{\circ} \mathrm{C}$ overnight. It is important to mention that 
REDV-N $N_{3}$ possess sequences with sensitiveness to elastases (Val-Gly-Val-Ala-ProGly, VGVAPG) which will be crucial for further cell infiltration and material colonization [28]. Not functionalized (NF) hydrogels with a closed structure and RGD-REDVfunctionalized (RR) gels were at $4^{\circ} \mathrm{C}$, while the NF scaffolds with an open structure were produced at room temperature, as will be described in the mechanical properties section

SVF-cells were thawed and added to the azide component at a concentration of 2.2 $x 10^{6}$ cells per construct. Both components were mixed and rapidly pipetted in sterile teflon ring molds (12 $\mathrm{mm}$ inner diameter) with an underlying sterile filter paper. A total volume of $150 \mu \mathrm{l}$ were used per construct, resulting after polymerization in a disc of 12 $\mathrm{mm}$ diameter and $1.1 \mathrm{~mm}$ for RR and NF open, and $0.9 \mathrm{~mm}$ thickness for NF closed structure hydrogels. Since the total volume used for the generation of the hydrogels was always the same, the difference in the thickness was mainly caused by the open versus the closed structure. Slow polymerization was achieved by keeping the constructs on ice for 15 minutes and at room temperature for another 15 minutes. Growth medium was added and the constructs were placed in the incubator for 15 minutes. To allow the direct perfusion of culture medium throughout the construct in the dynamic condition, channels were realized at the center of the disc-shaped cellbased hydrogels. An array of $4 \times 4$ channels (channel diameter $0.5 \mathrm{~mm}$; distance among channels from wall to wall $1 \mathrm{~mm}$ ) was punched by a custom-made device that ensures symmetrically aligned, uniform perfusion channels. In order to avoid any damage during the production process, hydrogels were formed on the top of a paper filter, which simplified the handling and the punching of the samples. The cell-based constructs were then placed between two silicone O-rings and transferred into perfusion-based bioreactors (available from Cellec AG, Switzerland) [30]. Unidirectional perfusion of growth medium was forced mainly through the previously punched channel array by a 
peristaltic pump (Ismatec SA, Reglo Digital MS-4/8) at a flow rate of $0.15 \mathrm{~mL} / \mathrm{min}$ for 5 days. Channeled cell-based hydrogel discs were cultured in static condition as control. Culture was performed in incubators at $37^{\circ} \mathrm{C}$ and $5 \%$ of $\mathrm{CO}_{2}$.

\subsection{In vivo implantation in ectopic rat model}

Animals were treated in compliance with Swiss Federal guidelines for animal welfare and all procedures were approved by the Veterinary Office of the Canton Basel (Basel, Switzerland) and conform to the Directive 2010/63/EU of the European Parliament. Rats were anesthetized by inhalation using a mixture of oxygen $(0.6 \mathrm{~L} / \mathrm{min})$ and Isoflurane (1.5-3 vol\%). Four constructs per animal were inserted in subcutaneous pockets created in the back of male nude rats $(\mathrm{Hsd}$ : $\mathrm{RH}-\mathrm{rnu} / \mathrm{rnu}$, Envigo, weight $252 \pm 16 \mathrm{~g} ; 8$ up to 12 animals were used per time point). NF-ELR or RR-ELR hydrogels were implanted right after cell encapsulation (not pre-cultured, NPC) or following culture in perfusion to assess the effect of dynamic pre-culture (PC) on the SVF angiogenic potential. Cell-free NF and RR- gels were used as control. After 3, 14 or 28 days upon implantation, rats were anesthetized by intraperitoneal injection of a mixture of Ketamine $(100 \mathrm{mg} / \mathrm{Kg})$ and Xylazin $(10 \mathrm{mg} / \mathrm{Kg})$ and sacrificed by exsanguination under the same anesthesia conditions as already described. The constructs were collected and embedded in OCT compound (Sakura Finetek, Torrance), and frozen in isopentane fumes cooled in liquid nitrogen. Preliminary results showed no difference in terms of vessel ingrowth, degradation of the constructs between samples implanted in the same animal from only one experimental group or two different experimental groups. Therefore, in the following experiments two samples from two different experimental conditions from the same donor were implanted in the same animal. 


\section{Analysis}

\subsection{Flow Cytometry}

The characterization of freshly isolated SVF cells from three donors was performed by using 6-channel cytofluorimetric analyses. Cell suspension was incubated for $30 \mathrm{~min}$ on ice with different fluorochrome-conjugated antibodies to human CD90 FITC, CD73 APC, CD31 FITC, CD34 APC-Cy7, CD146 PE, CD45 BV605, VEGFR2 PE, and CD11b APC (all from Biolegend) in staining buffer (PBS, 0.5\% v/v FBS, 2mM EDTA). Stromal mesenchymal cells, progenitor and mature endothelial cells, and myeloid cells were identified as $\mathrm{CD}^{-} 5^{-} \mathrm{CD} 3^{+} \mathrm{CD}^{+} 0^{+}, \mathrm{CD}^{-} 5^{-} \mathrm{CD} 31^{+} \mathrm{CD} 34^{+}, \mathrm{CD}^{-} 5^{-} \mathrm{CD} 31^{+}$ VEGFR2 ${ }^{+}$, and $C D 45^{+} \mathrm{CD}_{11} \mathrm{~b}^{+}$, respectively. Pericytes were identified as CD45- CD34CD146+, as previously described [31]. $5 \mu \mathrm{l}$ per million cells were used for all the antibodies according to the manufacturer's protocol, and data were acquired with LSRFortessaTM flow cytometer (BD Biosciences), analyzed using Flowjo v10.1r5 software (Tree Star), and presented as percentage over the living cells, positive stained for (4',6-diamidino-2-phenylindole) DAPI (Invitrogen).

\subsection{Histology}

For histological analysis, all samples were fixed with $1 \%$ paraformaldehyde at $4^{\circ} \mathrm{C}$ for about 18 hours followed by a treatment with $30 \%$ sucrose solution overnight.

For general histomorphological evaluation, cryosections were stained with Hematoxylin and Eosin (H\&E) according to standard protocols.

Immunofluorescence staining were performed on cryosections incubated for $1 \mathrm{~h}$ in $0.3 \% \mathrm{v} / \mathrm{v}$ Triton $\mathrm{X}-100$ and $2 \% \mathrm{v} / \mathrm{v}$ normal goat serum, or $5 \% \mathrm{v} / \mathrm{v}$ donkey serum in PBS (blocking buffer), and then for $1 \mathrm{~h}$ in the following primary antibodies: (i) mouse antihuman nuclei (dilution 1:100, clone 235-1, Millipore), (ii) anti-mouse PECAM-1 (dilution 1:100, CD31, Abcam), (iii) mouse anti-CD68 (dilution 1:100, AbD Serotec), (iv) rabbit 
anti-CD45 (dilution 1:100, Abcam), and (v) goat anti-vimentin (dilution 1:100, Santa Cruz). Subsequently, tissue sections were incubated in dark for $1 \mathrm{~h}$ in fluorescently labeled Alexa488, Alexa546, or Alexa647 (Invitrogen) secondary antibody at 1:200. Cell nuclei were stained with DAPI (Invitrogen).

For human ALU in situ hybridization, cryosections were digested with pepsin (0.5 $\mathrm{mg} / \mathrm{mL} 0.01 \mathrm{~N} \mathrm{HCL}$, Sigma) at $37^{\circ} \mathrm{C}$ for $10 \mathrm{~min}$, washed with PBS, and incubated at room temperature for $10 \mathrm{~min}$ in $0.1 \mathrm{~mol}$ TEAC (triethanolamine containing acetic acid). The sections were incubated for $30 \mathrm{~min}$ at $42^{\circ} \mathrm{C}$ in pre-hybridization solution (consisting of $20 \%$ SSC (trisodium-citrate-2-hydrate, $\mathrm{pH} 7$ ), Denhardt's solution 1\% (ficoll, polyvinylpyrrolidone and BSA solution in distilled water), 10\% dextransulfate, $1 \%$ salmon sperm DNA, 50\% deionized formamide and 18\% distilled water). The slides were incubated with ALU probe (Microsynth, $200 \mathrm{ng} / \mathrm{mL}$ ) and denatured at $95^{\circ} \mathrm{C}$ for 3 min, and incubated overnight at $42^{\circ} \mathrm{C}$. Sections were equilibrated with DIG-1 buffer at $\mathrm{RT}$ for 1 min (maleic acid and $\mathrm{NaCl}, \mathrm{pH} 7.5$ ) and blocked with $1 \%$ blocking reagent for 15 min at RT. Anti-digoxygenin staining was performed for 1 hour at RT (Roche). Successive washes with DIG-2 (DIG-1 buffer with 0.3\% Tween 20) and DIG-3 (Tris $\mathrm{HCl}, \mathrm{NaCl}$, and $\mathrm{MgCl} 2, \mathrm{pH}$ 9.5) were performed. The sections were finally incubated with NBT/BICP for 10 min, and the reaction was stopped with distilled water.

All images were acquired with Olympus BX63 fluorescent microscope (Olympus)

\subsection{Scanning Electron Microscopy (SEM).}

Structure and morphology of hydrogels and engineered tissues were evaluated using a scanning electron microscope (Nova NanoSEM 230, FEI). Constructs were fixed overnight in $2.5 \%$ glutaraldehyde in PBS, rinsed twice with distilled water and then passed in increasing ethanol solutions $(30,50,70,90$ and $2 \times 100 \% \mathrm{EtOH})$ for a minimum of 15-30 minutes per step. Samples were then lyophilized, sputtered with gold and then observed at an operating voltage of $15 \mathrm{kV}$. 


\subsection{DNA quantification}

Samples were digested overnight at $57^{\circ} \mathrm{C}$ in proteinase $\mathrm{K}$ solution $(1 \mathrm{mg} / \mathrm{mL}$ proteinase $\mathrm{K}, 50 \mathrm{mM}$ TRIS, $1 \mathrm{mM}$ EDTA, $1 \mathrm{mM}$ iodoacetamide, and $10 \mathrm{mg} / \mathrm{mL}$ pepstatin-A; SigmaAldrich) in double distilled water or potassium phosphate buffer. CyQUANT® Cell Proliferation Assay kit (Invitrogen) was used to quantify the DNA according to the manufacturer's protocol. The fluorescence was measured by using the excitation and emission wavelengths of 485 and 583, respectively, and a SpectraMax Gemini XS Microplate Spectrofuorometer (Molecular Devices). Samples were tested in duplicate for two donors for all the experimental groups.

\subsection{Angiogenesis array and Elisa assay}

A human angiogenesis proteome profiler antibody array (R\&D Systems, Inc.) was employed to assess the release of a broad range of angiogenic related factors released in supernatants of SVF cell-based RR, NF with an open or closed structure ELR constructs. Each spot boundary area was quantified by measuring the sum of the pixel intensities using ImageJ 1.47 software (Research Service Branch, NIH). Raw data from the proteome profile were presented as fold of increase of RR- and the NF-ELR groups. In particular, ratios of NF and RR or RR and NF were calculated and only the values $>2$-fold increase were considered and presented as percentages. The raw data of the proteomic profiler were also presented. The ELISA and array data were all normalized to the background and to the DNA amount. Samples were tested in duplicate for two donors.

The amounts of human Vascular Endothelial Growth Factor (VEGF) in either NF with an open and closed architecture or RR- based ELR hydrogels were measured in constructs and supernatants collected after 5 days in perfusion-based bioreactors by 
using ELISA kits (hVEGF: DuoSet DY293B-05, R\&D Systems according to manufacturer's instructions).

\subsection{Image Analysis}

Image analysis was performed by using (Image $\mathrm{J}, \mathrm{NIH}$ ) on 6 standardized field areas, with 3 fields acquired near the perfusion channels and in the middle of two perfusion channels (at $0.5 \mathrm{~mm}$ from the channel wall). Of those three fields, one was chosen at the bottom (in contact with the filter paper), one at the center and one at the top of at least three constructs per donor and per experimental group. The analyzed field in proportion to the whole sample area was about one-third of the total construct thickness. Images were acquired by using a 20x objective.

The spatial cell distribution was calculated as the number of DAPI-positive nuclei normalized by the area of the analyzed field.

The in vitro endothelial organization was assessed by counting the number of CD31+ cells either organized in elongated structures, resembling cord-like structures, or forming spot-like aggregates.

In vivo vessel length density (VLD) was quantified by measuring the length of the blood vessels normalized by the area of the image field.

All analyses were performed at least in two different biological samples in two independent experiments for the two donors used.

\subsection{Percentage of void calculation}

The void within the generated hydrogels was estimated by using the following equation [Zeng, 1999; Martin, 2009]:

$$
\text { Void }(\%)=\left(\left(W_{1}-W_{2}\right) / \rho_{\text {water }}\right) \times 100 / V_{\text {hydrogel }}
$$

where $W_{1}$ and $W_{2}$ are the weight of the swollen and lyophilized gels, respectively, $\rho_{\text {water }}$ is the density of pure water and $V_{\text {hydrogel }}$ is the volume of the wet gel $\left(V_{\text {hydrogel }}=\pi r^{2} h\right.$, 
where $r$ and $h$ are the radius and height of the cylindrical sample, respectively). Five samples of each kind of hydrogel were measured blotted dry on paper tissue to remove the excess of surface water before each measurement.

\subsection{Mechanical properties}

Solutions of the ELR-Cyclo and ELR-N3 were prepared in PBS $(50 \mathrm{mg} / \mathrm{mL}$ and with a molar ratio of $1: 1$ ) and kept at $4{ }^{\circ} \mathrm{C}$ for at least $24 \mathrm{~h}$. NF closed and RR gels were obtained by simply mixing $300 \mu \mathrm{L}$ of each solutions (ELR-Cyclo and ELR-N3) at $4{ }^{\circ} \mathrm{C}$ inside the appropriate mold (diameter: $12 \mathrm{~mm}$; height: $2 \mathrm{~mm}$ ). After 15 minutes at $4{ }^{\circ} \mathrm{C}$, the gels were removed from the mold and kept in PBS at r.t. for 15 minutes. Then rheological tests were performed. NF open gels were obtained by mixing $300 \mu \mathrm{L}$ of each solutions (ELR-Cyclo and ELR-N3) at r.t inside the appropriate mold (diameter: $12 \mathrm{~mm}$; height: $2 \mathrm{~mm}$ ). After 15 minutes at r.t., the gels were removed from the mold and kept in PBS at r.t. for 15 minutes. Rheological experiments were performed using a strain-con-trolled AR-2000ex rheometer (TA Instruments) with the hydrogel submerged in water. Cylindrical swollen gel samples were placed between parallel plates of nonporous stainless steel (diameter $=12 \mathrm{~mm}$ ) and the gap between the plates was adjusted using a normal force of $0.2 \mathrm{~N}$ in order to prevent slippage. Measurements were carried out at $37^{\circ} \mathrm{C}$, with the sample temperature being controlled and maintained using a Peltier device. Three different samples of each kind of hydrogels were measured in shear deformation mode. A dynamic strain sweep (with amplitudes ranging between 0.1 and $20 \%$ ) was carried out at a frequency of $1 \mathrm{~Hz}$ to measure the dynamic shear modulus as a function of strain. Then, dynamic frequency sweep tests were performed to determine the dependence of the dynamic shear modulus and loss factor on frequency. 


\section{Statistical analysis}

Data were evaluated by analysis of variance one-way ANOVA followed by Bonferroni's post-hoc test for multiple comparison or by nonparametric Mann-Whitney test using Prism 5 (GraphPad, La Jolla, CA). $P<0.05$ was considered statistically significant. All data are presented as a mean \pm standard deviation. 


\section{Results}

In this study, we first investigated the suitable culture condition between static and dynamic condition to promote the in vitro pre-vascularization of ELR-hydrogels in terms of endothelial cell organization and cell density (Figure 1). Once the perfusionculture was shown to promote a superior cord-like organization by endothelial cells, we cultured the SVF cells only in perfusion condition to investigate the role of hydrogel functionalization and architecture in terms of angiogenic potential and host response in a nude rat subcutaneous pocket model (Figure 1).

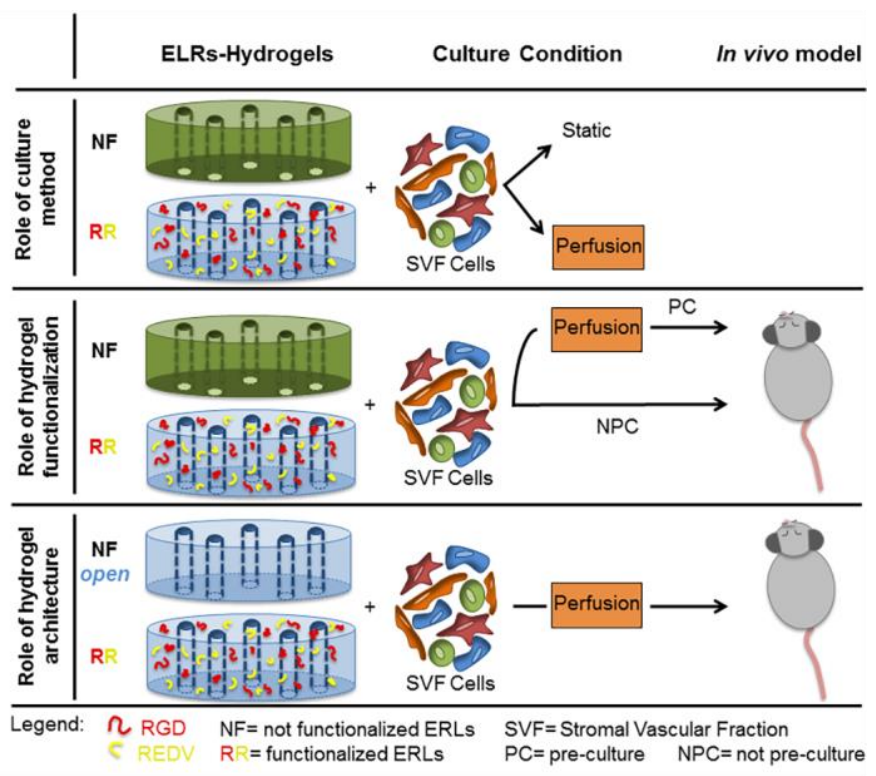

Figure 1. Scheme of the study. Summary of the main steps of the study.

In vitro culture of ELRs-based constructs

Freshly isolated SVF cells from the three donors used were composed predominantly of mesenchymal stromal cells $\left(46.2 \pm 12.8 \%\right.$ CD45 $^{-}$CD73 $^{+}$CD90 $\left.{ }^{+}\right)$, progenitor $(9.9 \pm$ $\left.0.9 \% \mathrm{CD}^{-} 5^{-} \mathrm{CD} 1^{+} \mathrm{CD}^{+} 4^{+}\right)$and mature $\left(0.3 \pm 0.06 \% \mathrm{CD}^{-} 5^{-} \mathrm{CD} 31^{+} \mathrm{VEGFR}^{+}\right)$ endothelial cells, pericytes $\left(6.7 \pm 0.7 \%\right.$ CD $^{-} 5^{-}$CD34- ${ }^{-}$CD146 $\left.{ }^{+}\right)$, and myeloid cells $(11.2$ $\pm 1.3 \% \mathrm{CD}^{2} 5^{+}$CD11 $\mathrm{b}^{+}$) (Suppl. Fig. 1A-B). 
To investigate the in vitro capacity of pre-vascularization human adipose tissuederived SVF cells were first encapsulated in NF or RR- based ELR hydrogels and then cultured either in static or under perfusion conditions.

Following embedding in NF or RR- ELR, the SVF cells were uniformly distributed throughout the entire volume of the constructs in both static and perfusion culture conditions (Fig. 2A). The cell density quantified at the bottom, center and top region of the constructs was evenly distributed in all experimental conditions. However, the perfusion culture differently affected the number of cells present in the NF and RRELR: the cell number significantly increased in the functionalized hydrogel whereas it was considerably reduced in the NF control group (Fig. 2A). The static culture instead maintained a similar cell density in both NF and RR- ELR (Fig. 2A). Scanning electron microscopy confirmed that cell adherence on NF ELR was low: cell morphology was rather round and few connecting cell processes were present (Fig. 2B). However, in perfusion-based culture few SVF cells displayed a more elongated morphology with a slight increase of the connecting cellular processes. In contrast, most of the cells embedded in RR-ELR completely adhered to the biomaterial, displaying a more elongated, flat morphology and with an increased number of protrusions (Fig 2B). The effect observed for RR-ELR was further increased when perfusion culture was used: a remarkable organization into flat elongated parallel cells was observed in scattered area of the perfusion channels and numerous filopodia-like structures were observed (Fig. 2B). 

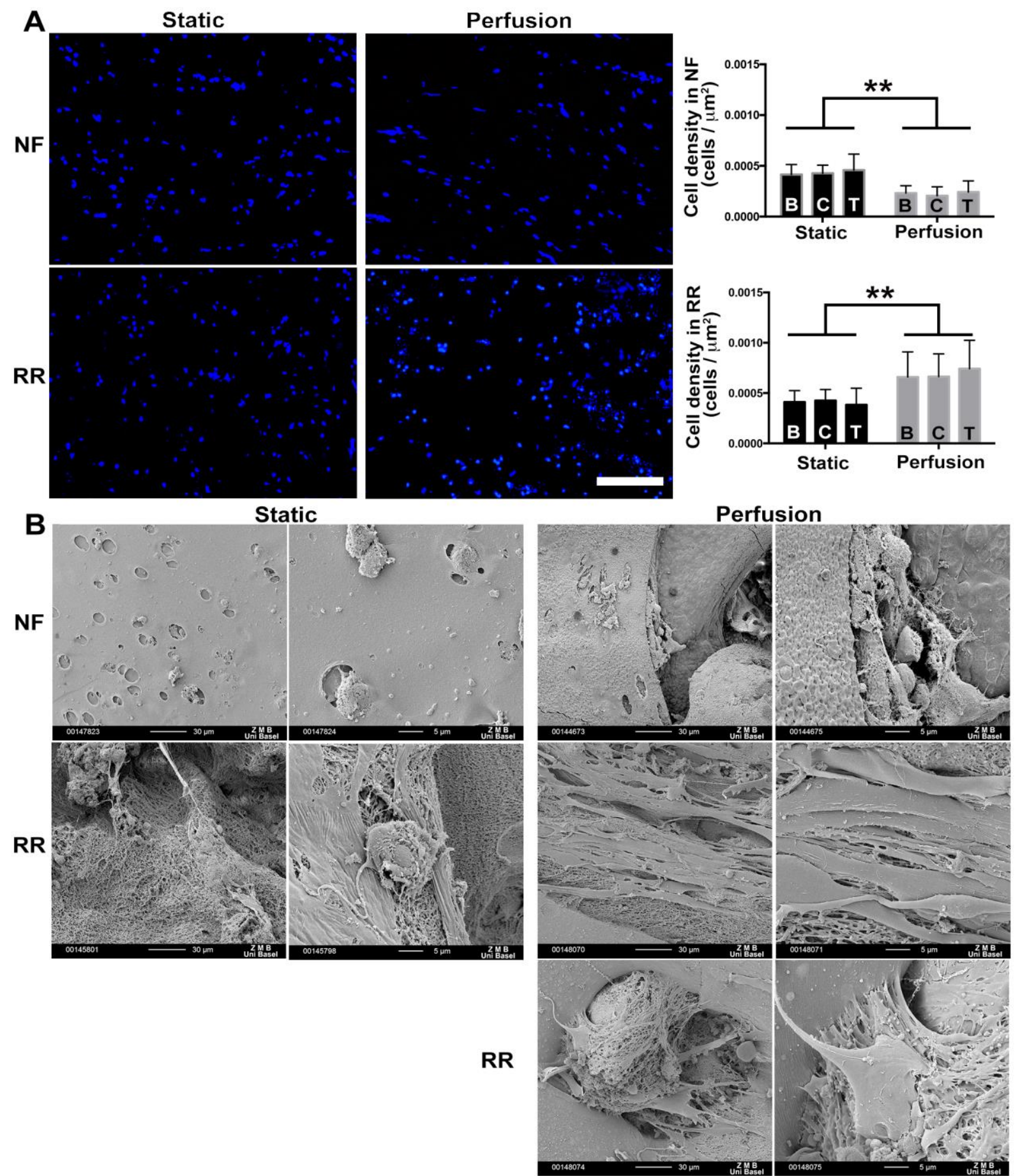

Figure 2. SVF cell-based ELR construct characterization. (A) Staining for DAPI (blue) of SVF cells cultured in NF and RR- functionalized ELR gels in either static or perfusion condition. Quantifications of cell density (cells $/ \mu \mathrm{m}^{2}$ ) by image analysis were done for static and perfusion cultured constructs generated either with NF or RR- ELR hydrogels in three different location in order to cover the entire thickness of the engineered tissues: Bottom (B); Center (C); and Top (T) (by image analysis of DAPIstained sections). Scale bar $=100 \mu \mathrm{m}$. (B) Scanning electron microscopy images of constructs generated in NF or RR-ELR after culture in static or perfusion at low and high magnifications (scale bars $=30$ and $5 \mu \mathrm{m}$, respectively). In the static condition, images are representative of the surface of SVF-embedded hydrogels. In the perfusion condition, images from the first two rows (NF and RR) represent cells close to the 
channels whereas the last row images show the surface of SVF-embedded RRhydrogels.

Immunostaining specific for PECAM-1 (CD31) revealed that endothelial cells were almost exclusively encapsulated as single cells within the NF ELR, whereas in RRhydrogels they formed either only aggregates during static culture or aggregates and elongated cord-like structures in dynamic conditions (Fig. 3A). Cell clusters in unorganized assemblies of either 3 or $4-5$ or more than 5 cells were quantified in RRELR-based constructs cultured in both static and dynamic conditions (Fig. 3B). Cell aggregates in static conditions were composed of only few cells $(<5)$ and preferentially formed close to the edge of the channels (Fig 3B). However, in perfusion culture the formed cell aggregates were instead larger and present in an equal number proximally or distally of the perfused channels. Solely culture under perfusion conditions supported the organization of $\mathrm{CD} 31^{+}$cells in elongated cord-like structures, which mainly formed distally to the channels (Fig. 3B). Further analyses of the angiogenic proteome profiles were only performed on the engineered tissues generated under perfusion conditions since the dynamic conditions appeared to promote in vitro cell adhesion and vascular organization.

Perfusion-based culture in NF or RR-ELR significantly affected the profile of proand anti- angiogenic factors released by SVF cells (Fig. 3C). SVF cells cultured in NFELR mostly upregulated (79\%) the release of anti-angiogenic factors, including Insulin Growth Factor Binding Protein-3 (IGFBP-3) [32], prolactin [33], angiostatin [34] or vasohibin [35] (Fig. 3C). Only $21 \%$ of the upregulated factors in NF ELR are described in the literature to have a pro-angiogenic effect such as Fibroblast Growth Factor (FGF) acidic and Interleukin-8 (IL-8) [36]. On the contrary, SVF cells cultured in functionalized ELR mainly upregulated the release of factors known as pro-angiogenic $(70 \%$ of the upregulated factors were proangiogenic) (e.g. Monocyte chemoattractant protein-1 
(MCP-1) [37], Insulin Growth Factor Binding Protein-2 (IGFBP-2) [38], Heparin-binding

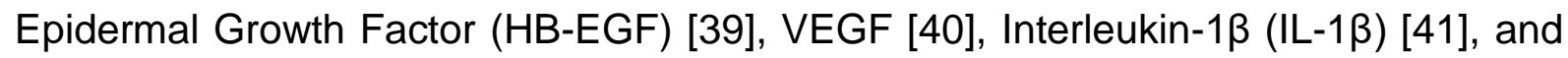
urokinase-type plasminogen activator (UPA) [42]). Among all the investigated factors, SVF cells upregulated the expression of proteases, namely Dipeptidyl peptidase-4 (DPPIV) and Matrix Metallopeptidase 9 (MMP-9), and of growth factors, namely Platelet Factor 4 (PF4), persephin, and endothelin-a in both RR and NF closed structure hydrogels (Suppl. Fig. 2).

Further quantification by ELISA assay showed that VEGF, one of the most potent angiogenic factors, showed, was mainly released in the supernatant of RR-ELRbased constructs and was not retained in the engineered tissue itself (Fig. 3D). SVF cultured in NF-ELR appeared not to release a significant amount of VEGF, which was in low amount retained within the construct and not detectable in the supernatant. 

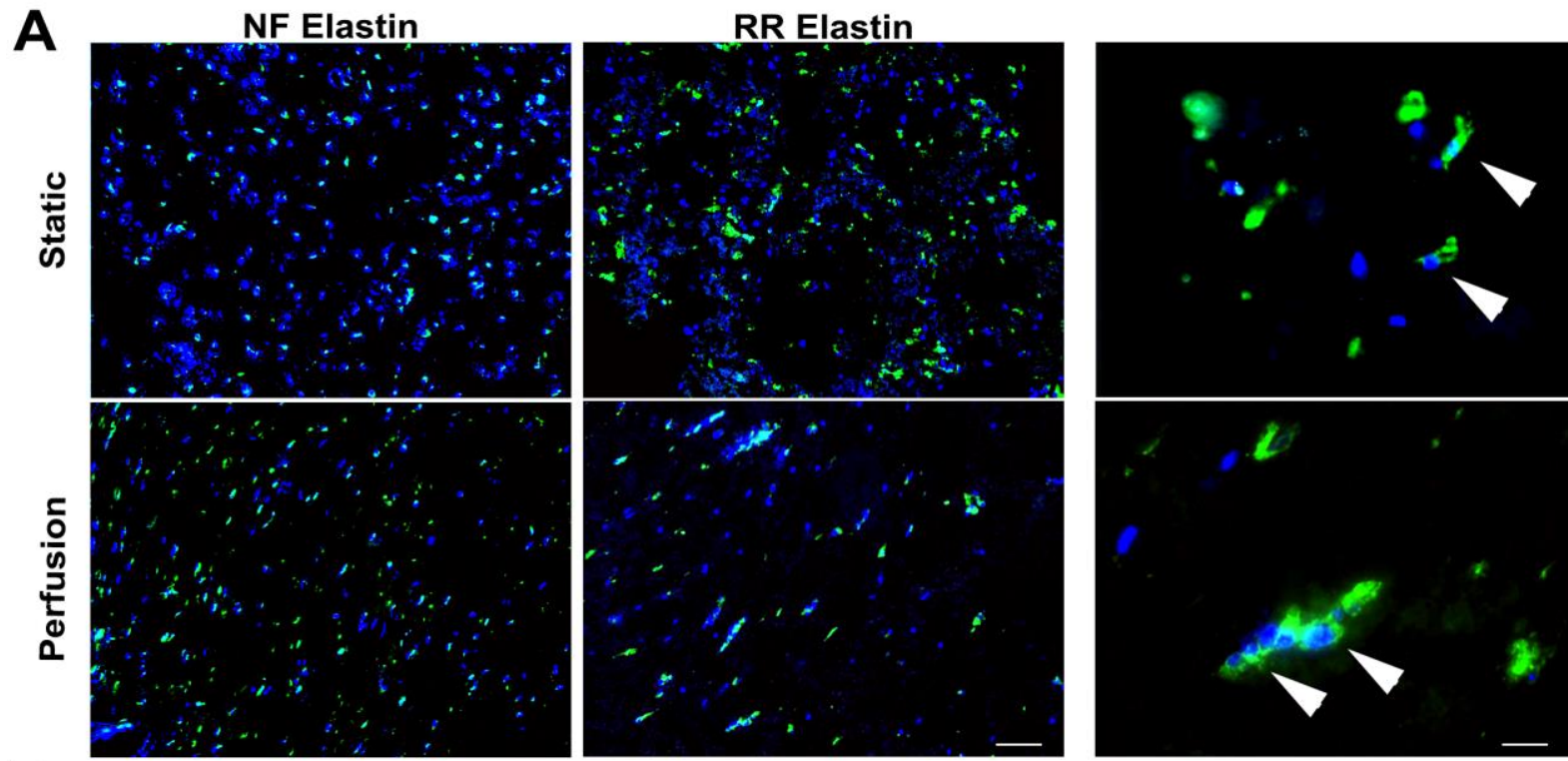

B
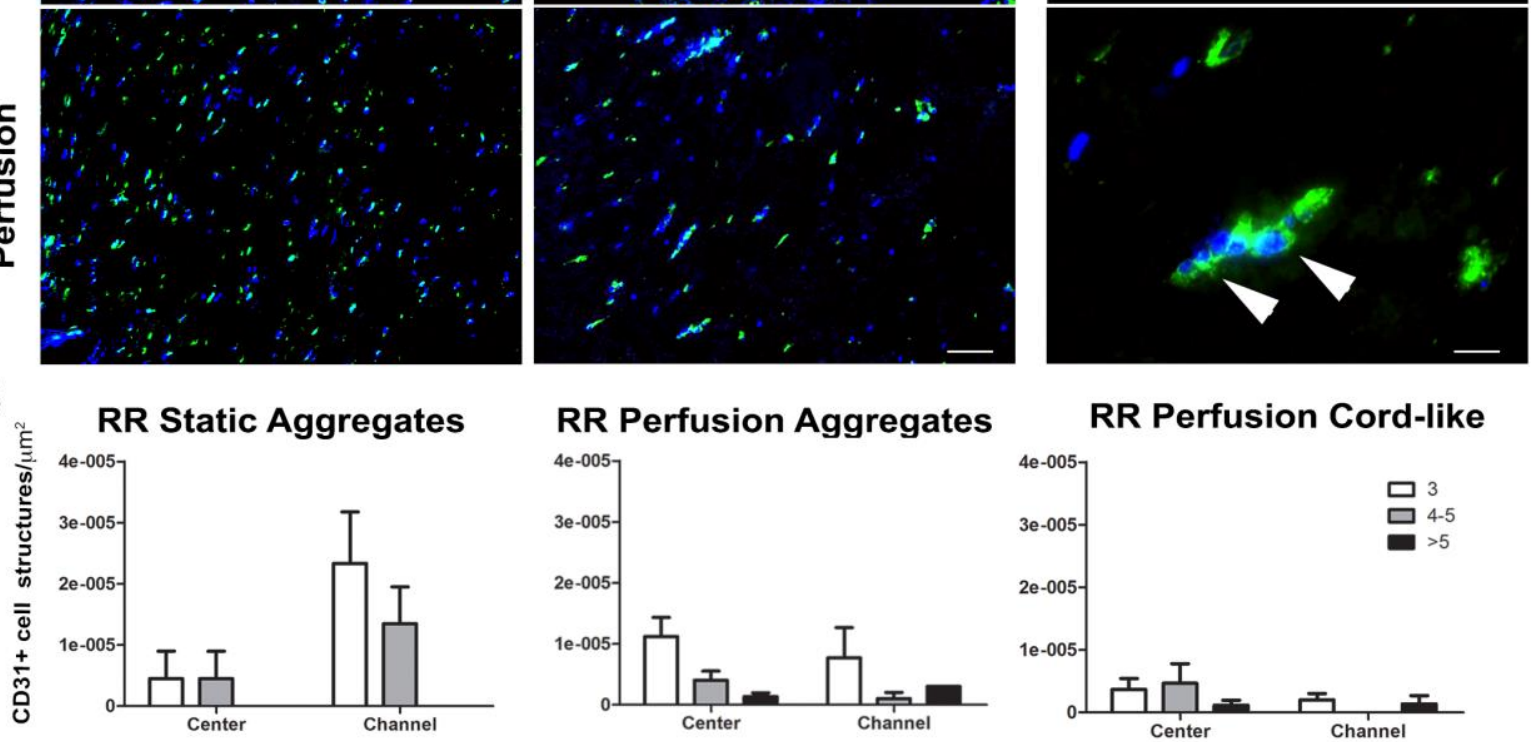

RR Perfusion Cord-like

C

SVF in NF-elastin

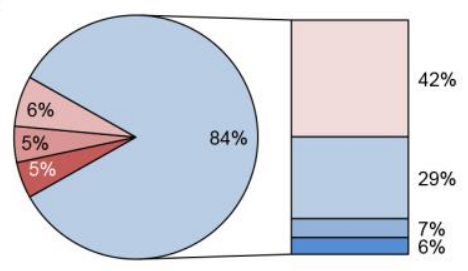

$\square$ Artemin

口FGF acidic

미L-8

ㅁIGFBP-3

口Prolactin

$\square$ Angiostatin/Plasminogen

$\square$ Vasohibin

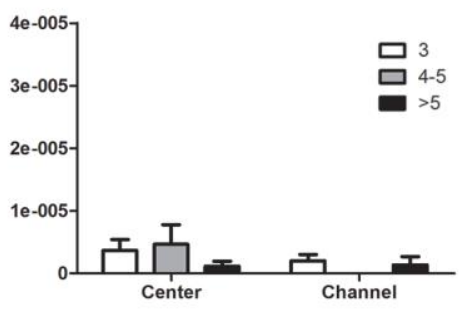

SVF in RR-elastin

D

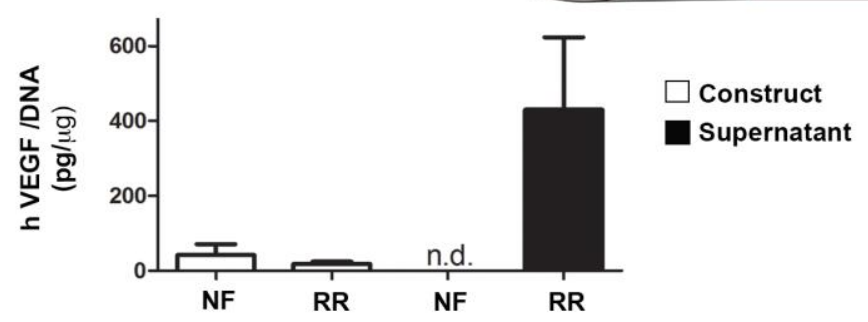

Figure 3. In vitro angiogenic potential of SVF cell-based ELR constructs.

(A) Immunofluorescence staining for CD31 (green) of constructs generated by SVF cells in either NF or RR- ELR in static or perfusion-based culture at low (left) and high (right) magnifications. Nuclei were stained with DAPI (blue). High magnifications were provided only for the RR-ELR condition to distinguish between the formation of cell aggregates and cord-like structures. White arrow heads indicate the specific staining for endothelial cells. Scale bars $=100$ and $20 \mu \mathrm{m}$, for low and high magnification, respectively. (B) Quantification of $\mathrm{CD} 31^{+}$cell aggregates formed in static or perfusion culture and cord-like structures in perfusion in areas proximal (channel) or distal (center) to the perfusion channels. Both aggregates and cord-like structures were distinguished by the number of endothelial cells included in them $(3,4$ or 5 , more than 
5). (C) Pie graph representing all the upregulated factors in NF (left) or RR- (right) ELR constructs generated in perfusion culture, divided into pro- and anti- angiogenic factors. (D) Quantification of VEGF released by and entrapped in constructs generated in NF or RR-ELR in dynamic condition. $p<0.001$. Number of replicates $=4$ from two independent experiments (B-D).

Engineered tissues generated in perfusion culture were further assessed for their in vivo angiogenic potential. Upon implantation in a subcutaneous pocket in nude rats, blood vessel infiltration at any time point was efficiently blocked by NF-ELR alone or in combination with SVF cells either pre-cultured or freshly encapsulated (Fig. 4A). Vessel ingrowth was observed only through the preformed perfusion channels (indicated by $c$ in Fig. 4A) of the constructs. On the contrary, RR-ELR supported blood vessel infiltration from the earliest time point ( 3 days) and the constructs were completely invaded by host vascularization following 28 days in vivo. Infiltration of vessels preferentially initiated through the perfusion channels within the constructs and with time spread throughout the entire constructs. Quantification of vessel length density in RR-ELR showed that the presence of SVF cells (either pre-cultured or freshly loaded) significantly enhanced the vessel ingrowth into the implants compared to the cell free (empty) hydrogels at early time point (Fig 4B). Following 28 days in vivo, implants with not-pre-cultured SVF cells had a higher amount of vessels within the implant. 

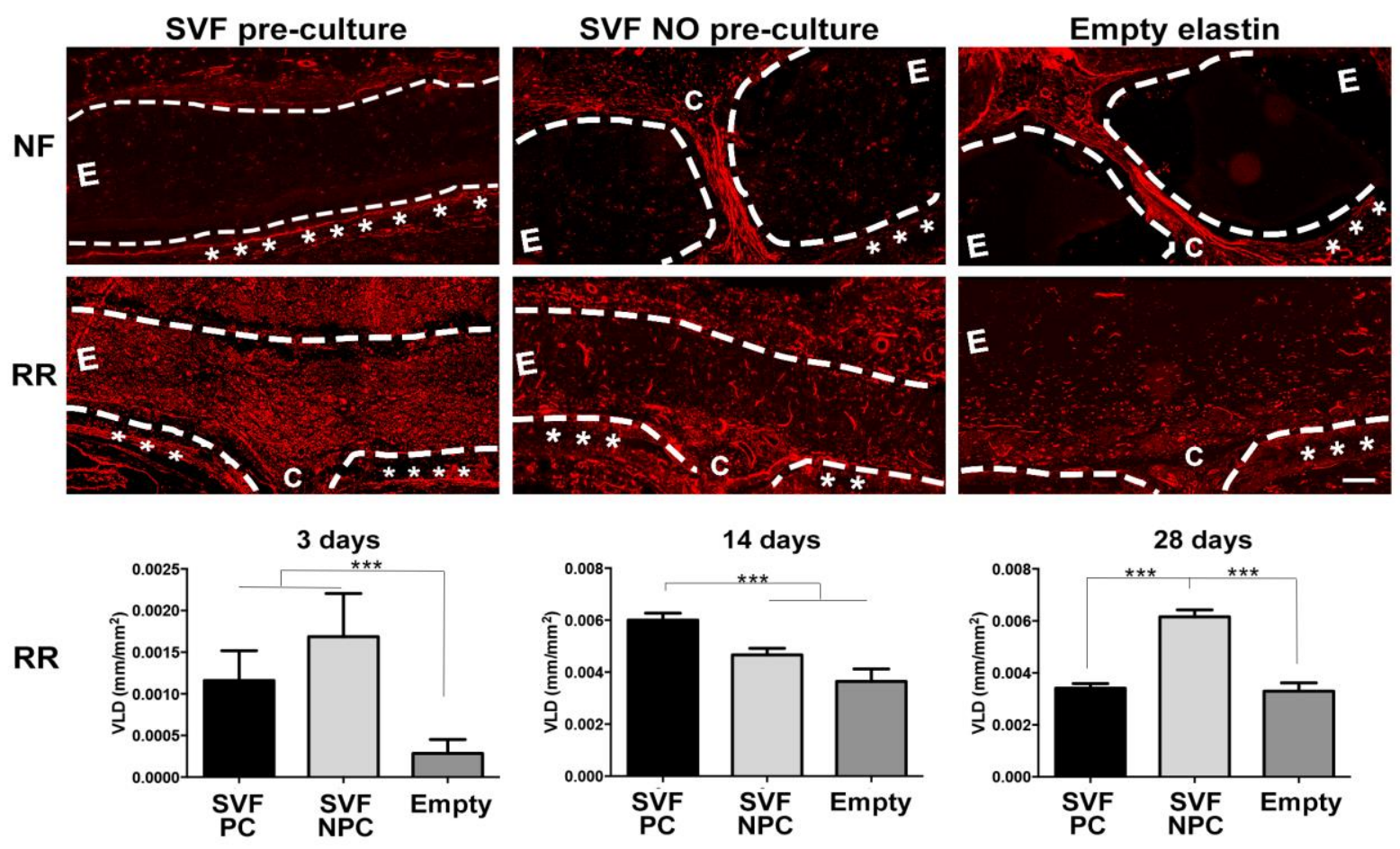

Figure 4. In vivo angiogenic potential of SVF cell-based ELR constructs.

(A) Representative immunofluorescence images specific for endothelial cells (CD31+ cells) of NF or RR elastin with SVF cultured in perfusion-based bioreactors (SVF pre-culture) or freshly loaded (SVF NO pre-culture). Cell-free ELR hydrogels (empty) were used as a control. All experimental groups were analyzed after 28 days in vivo. The letters $\mathrm{E}$ and $\mathrm{C}$ indicate the ELR-based construct and the preformed perfusion channels, respectively. The dashed line outlines the perimeter of the implant, whereas the * marks the paper filter, which is located at the bottom of the implant. Scale bar $=100 \mu \mathrm{m}$. (B) Quantification of VLD of only RR-ELRs was assessed for constructs generated with SVF pre-cultured (SVF PC) or freshly encapsulated (SVF NPC) and for empty hydrogels (Empty). ${ }^{* *} p<0.0001$.

In agreement with the inhibition of vessel ingrowth, NF-ELR based constructs also remarkably reduced the amount of host cell infiltration, which was restricted to the area near the preformed channels (Fig. 5). The hydrogel was entirely present up to 28 days in vivo. RR-ELR based constructs instead were not visible anymore after 3 days in vivo and they led to a typical foreign body reaction.

At an early time point an inflammatory infiltrate dominated by neutrophilic granulocytes and macrophages was observed both in the contact with the paper filter and the host tissue (Suppl. Fig. 1A-B; left row; Suppl. Fig. 5B). Moreover, an inflammatory response 
was detected within the channels as well. From day 14 on, a cellular granulation tissue developed with a mixed inflammatory infiltrate consisting of neutrophils, lymphocytes, and macrophages (Suppl. Fig. 3A, black arrows in Suppl. Fig. 3B; central row; Suppl. Fig. 4B). At 28 days the granulation tissue was replaced by a cellular scar-like tissue with numerous small vessels and scattered residual neutrophils and macrophages (Suppl. Fig. 3A-B; right row, 3C-D; Suppl. Fig. 4B). Only small granulomas were detected, which were mainly composed of two macrophages. Immunofluorescence staining for vimentin (fibroblasts) and CD45 allowed for a better distinction between the fibroblasts and the inflammatory cells. After 3 and 14 days in vivo we observed numerous fibrocytes (both vimentin and CD45 positive cells), which decreased at a later time point (Suppl. Fig. 4A).
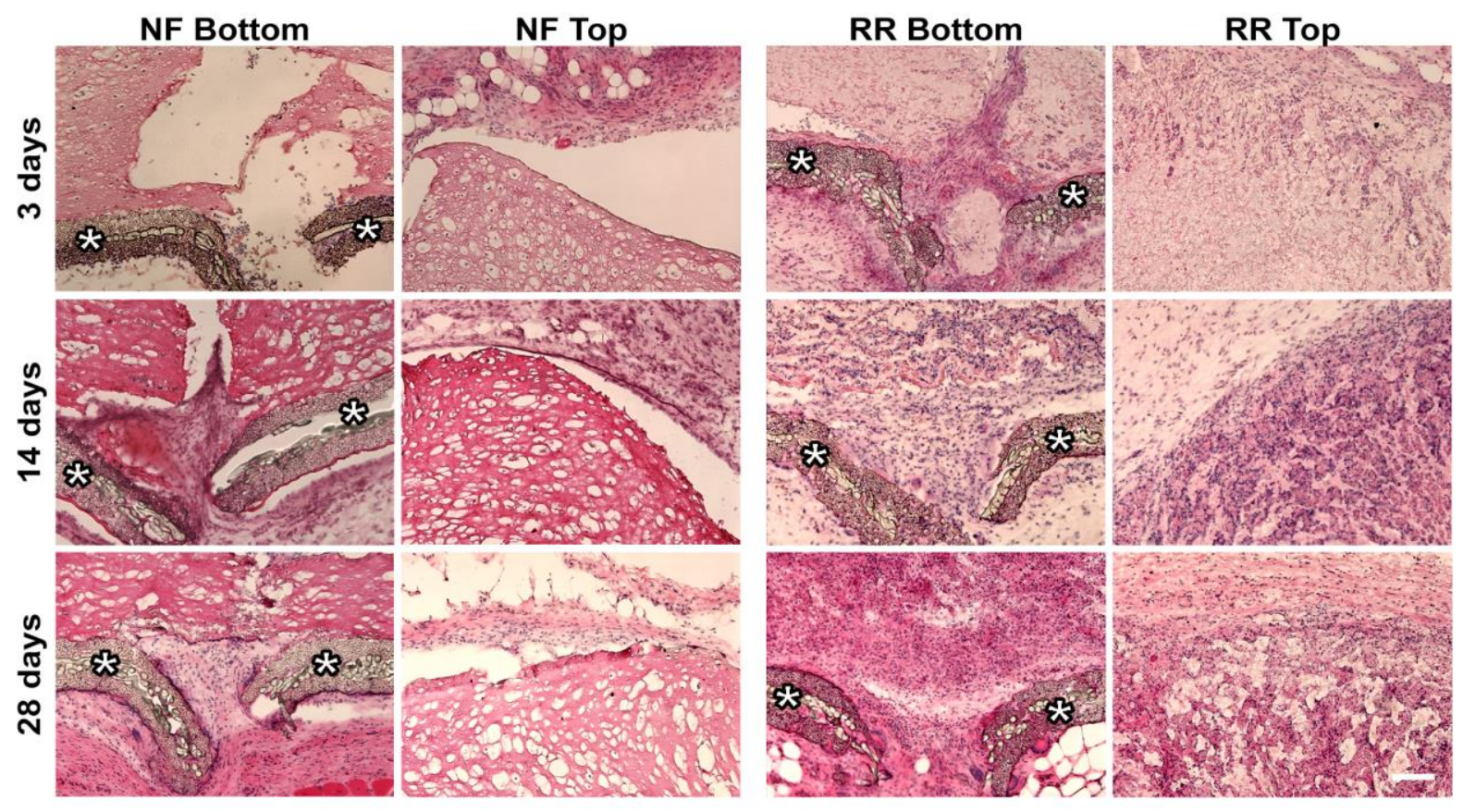

Figure 5. In vivo host response to SVF cell-based ELR implants.

Staining for hematoxylin and eosin of SVF cell-based constructs cultured in perfusionbased bioreactors in either NF or RR- ELR hydrogels after 3, 14 or 28 days in vivo. Representative images of the bottom (in contact with the paper filter) and the top parts of the implants (in direct contact with the host tissue). The * marks the paper filter, which is located at the bottom of the implant. Scale bar $=100 \mu \mathrm{m}$. 
We also investigated the role of the hydrogel architecture on the infiltration properties of the blood vessels. Indeed, after polymerization, the RR- and NF-ELR resulted to have a different structure: the first one was composed of large openings completely connected to each other (resembling a non-woven sponge), while the second consisted of a dense uniform hydrogel with single unconnected small pores, mostly hosting only single cells (Suppl. Fig. 5A). Therefore, we added the experimental group of NF-ELR hydrogel polymerized at room instead of ice temperature to obtain the NF hydrogel with an open structure, resembling the one of the RR-ELR. These NF open hydrogels showed an open structure similar to the RR-hydrogels (Fig. 6A) with void volume higher than $80 \%$ and significantly different to the NF hydrogels with a closed structure and void volume lower than $65 \%$. The mechanical properties resulted to be similar in case of RR and NF open ELRs-hydrogels and statistically different from the NF with a closed structure (Suppl. Fig. 6). NF with a closed structure showed a statistically significant increase in both the storage (G') and the loss (G') moduli (Suppl. Fig. 6A), and in the complex module and $\delta$ compared to the RR and NF hydrogels with an open structure. NF closed ELRs-hydrogels resulted in higher mechanical properties than RR and NF open ELRs-hydrogels which means that their closed structure drives to a better storage of the applied energy. RR and NF open ELRs-hydrogels showed lower values of $\tan \delta$ than NF closed ELRs-hydrogels, which means that these hydrogels possess better elasticity than NF closed ELRs-hydrogels [23] .

Scanning electron microscopy showed that in static culture SVF cells displayed mostly a round shape with few adhesion processes in the open structure NF-hydrogel, similarly to what has been observed in the closed NF ELR (Suppl. Fig. 5B). However, perfusion culture allowed a better elongation of the cells in the NF with open structure (Suppl. Fig. 5B) compared to the NF closed ELR (Fig. 2B). Moreover, SVF cells cultured in NF-ELR with an open structure resulted in having no detectable amount of 
VEGF contained in the engineered tissue and $22.9 \pm 32.4 \mathrm{pg} / \mu \mathrm{g}$ released in the supernatant, which was six-times lower compared to RR-ELR based constructs (Fig. 3D). The proteome profiler was employed to screen for the 55 soluble angiogenesis released by the SVF cells also following the perfusion-culture in NF open structure hydrogels (Suppl. Fig. 2C). Only few factors, namely Endothelin-a, IL-8, Serpin E1, and Thrombospondin-1, were slightly upregulated in the SVF-based NF open hydrogels. Although the empty RR- and open structure NF-ELR-based scaffolds had similar pore architecture (Fig. 6A), the host blood vessels infiltrated these biomaterials in different ways, showing that functionalization plays a key role (Fig. 6B). Quantification of vessel length density showed indeed that functionalized hydrogels allowed a statistically superior infiltration of blood vessels (Fig. 6C).

A RR

NF NF open
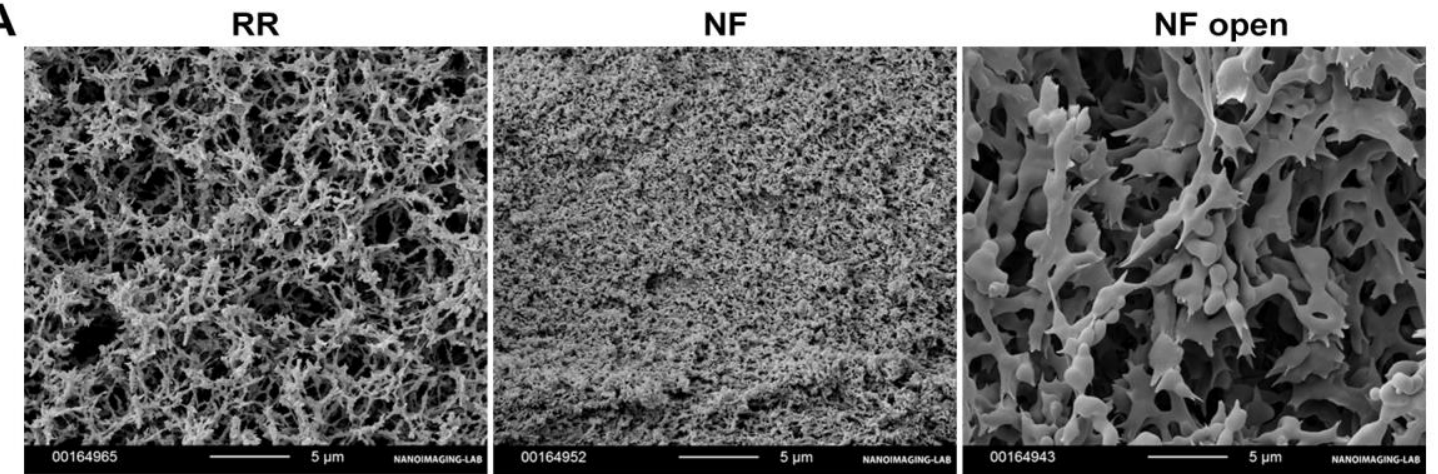

B

Empty RR

Empty NF open

C
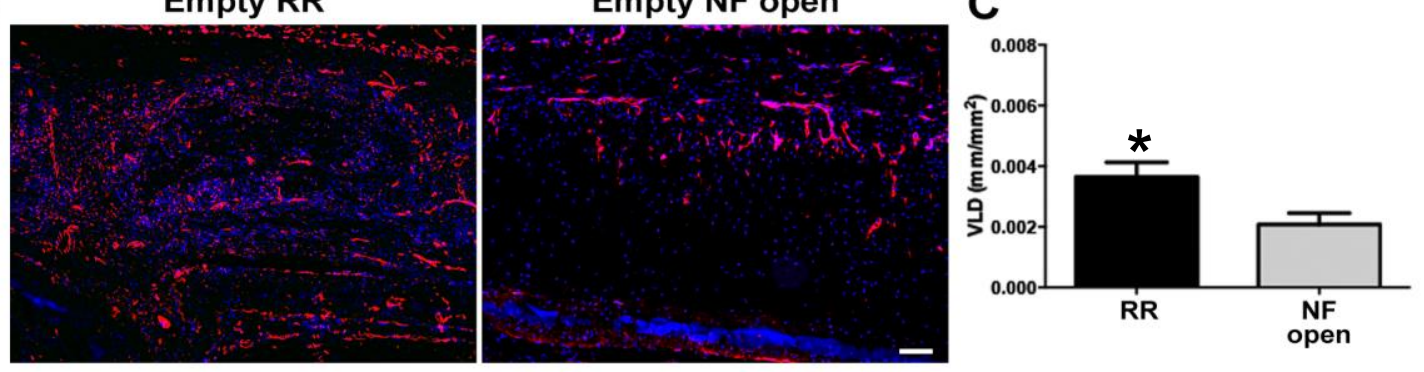

Figure 6. Construct structure and vessel infiltration.

(A) Representative scanning electron microscopy images of cell-free hydrogels: either $\mathrm{RR}$ or NF and NF open (scale bar $=5 \mu \mathrm{m}$ ). (B) Immunofluorescence images for endothelial cells (CD31 in red) of cell free implants (empty) generated with only open structure either RR- or NF open ELR after 14 days in vivo. Nuclei were stained with DAPI (blue). Scale bar $=100 \mu \mathrm{m}$. (C) Quantification of the VLD in cell free functionalized (Empty RR) or not functionalized open structure (Empty NF open) ELR 
following 14 days in vivo. Number of replicates $=4$ from two independent experiments. ${ }^{*} p=0.039$.

Contrary to NF hydrogels with a closed structure, NF with an open architecture, after 3 days in vivo, allowed the infiltration of some inflammatory cells (e.g. neutrophilic granulocytes) especially on the side in contact with the host tissue. Nevertheless, the host cell infiltration resulted in being reduced in NF open compared to RR- ELRs (Fig. 7). At 3 and 14 days in vivo, NF hydrogels with an open structure showed a prevailing cell infiltration in contact with the host tissue (NF open Top) rather than at the channel sites (NF open Bottom). At 28 days the hydrogel was still present and largely infiltrated by neutrophils and macrophages. Always at later time point, similarly to the cell-loaded RR-ELRs in the cell-free functionalized hydrogels, the granulation tissue existing at the edges of the implant was replaced by a scar-like tissue with small vessels and few neutrophils and macrophages, mainly invaded by fibroblast-like cells. In NF hydrogels with an open structure, the inflammation process appeared delayed and less strong compared to the functionalized ELRs.
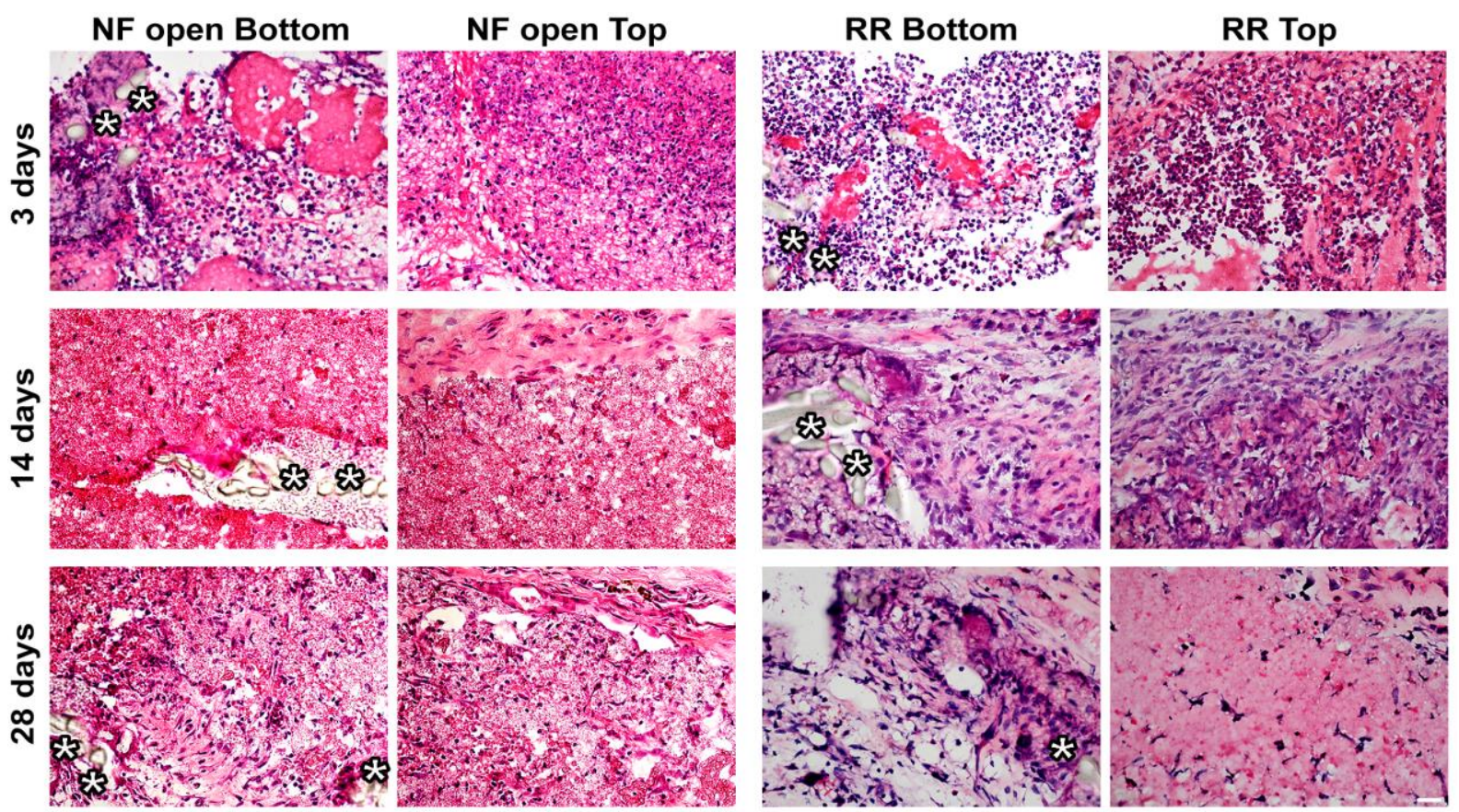


\section{Figure 7. In vivo host response to cell free ELR implants.}

Staining for hematoxylin and eosin of SVF cell-free constructs in either NF with an open structure or RR- ELR hydrogels after 3, 14 or 28 days in vivo. Representative images of the bottom (in contact to the paper filter) and the top parts of the implants (in direct contact with the host tissue). The * marks the paper filter, which is located at the bottom of the implant. Scale bar $=20 \mu \mathrm{m}$.

Human implanted cells were difficult to detect in the RR-ELR based constructs at alltime points. On the contrary, few SVF cells pre-cultured in NF-ELR were still present after 3 and 28 days in vivo (Fig. 8A-B). Quantification of human cells showed that there was a significant drop in cell amount from day 3 to 14. A similar amount of cells was found after 14 and 28 days in vivo (Fig. $8 \mathrm{C}$ ).
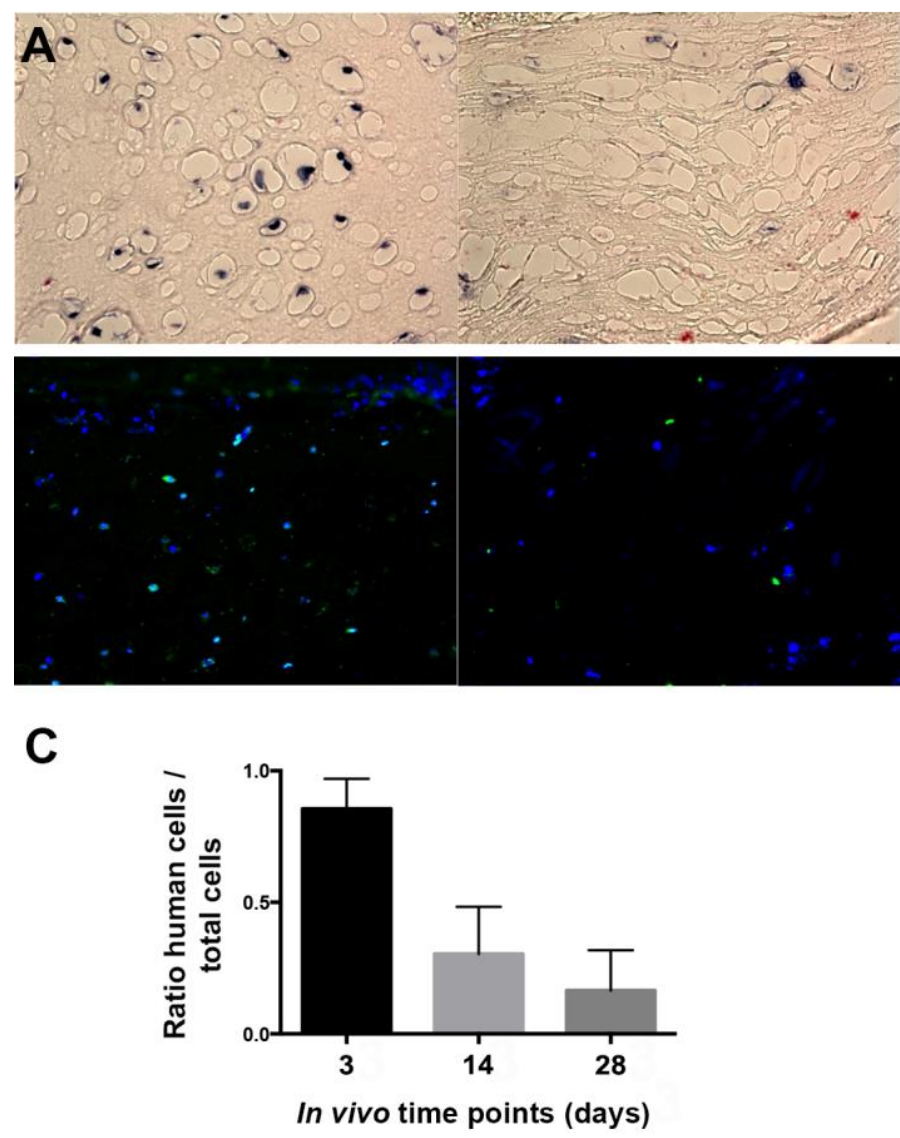

Figure 8. In vivo presence of implanted human cells.

(A) Representative images of human ALU in situ hybridization and (B) immunofluorescence staining with specific human nuclei (green) for SVF-based NF ELR after 3 (left) and 28 (right) days. Nuclei were stained with DAPI (blue). (C) Quantification of the ratio of human cells (stained positive with specific human nuclei) to the total amount of cells (stained with DAPI) present in parallel sections of the same construct generated with SVF pre-cultured in NF ELR in perfusion bioreactors. Scale bar $=20 \mu \mathrm{m}$. Number of replicates $=4$ from two independent experiments. 


\section{Discussion}

Achieving the control over the vascularization of engineered tissues upon implantation is crucial in order to enhance the therapeutic efficacy of cell-based strategies for regenerative medicine. In our study, we propose the employment of artificial elastinbased extracellular matrices not only as a mere vehicle for cell delivery to the damaged tissue, but also as a key regulator of cellular interactions with different host cells, which can also modulate the vascularization of the implant and its integration into the surrounding native tissues. Moreover, these elastin-based scaffolds have shown a great capacity to adapt and change their properties to match the specific needs of the tissue/organ to be regenerated. Our findings showed that the change of the bioactive properties of the ELR hydrogels can on its own significantly modulate the implant interaction with the host and the vascularization potential of highly angiogenic cells, as adipose tissue-derived SVF. Regardless of the open pore structure of the scaffolds made of RR-gels, the different bioactivities (RGD, REDV and VGVAPG) present in the RR-gels, enhance cell adhesion and trigger the vascularization process due to mainly two basic aspects of the bioactivity of these ELRs. Firstly, the presence of both general cell adhesion sequences (RGD) and specific endothelial cell adhesion sequences (REDV) previously described by Hubbell et al. [43], which together function as a trigger agent for the adhesion and spreading of the proangiogenic cells. Secondly, the presence of the VGVAPG sequence that is well demonstrated to be chemotactic for monocytes and sensitive to proteolysis by elastolytic enzymes [44]. This sequence promotes a cell guided degradation of the RR-gels by recruitment of monocytes that will help matrix colonization, opening the way to further cells like endothelial cells and fibroblasts as confirmed by the histological images. The number of monocytes and 
macrophages decreases after host cells colonize and vascularize the scaffold, and they may only be found in few numbers after 28 days.

Freshly isolated SVF cells were reported to possess a superior capacity to generate in vitro microvessels compared to other prevascularization approaches based on the coculture of endothelial cells and either mesenchymal stem cells or perivascular cells [6]. Compared to static culture, direct perfusion promoted cell adhesion also in NF hydrogels, but boosted cord-like organization only when SVF cells were seeded in RRELR gels, and therefore, perfusion was identified as a suitable culture condition to promote the angiogenic potential of SVF and was further investigated in vivo. It was not observed a significant effect on early vascularization between the implantation of constructs generated with cells pre-cultured in perfusion or freshly embedded. These findings would ease the possible clinical translation of the proposed treatment by promoting an intra-operatively approach. Moreover, the SVF appeared to have a role in accelerating the vascularization in RR hydrogels as compared to cell free-scaffolds, although their survival in vivo was limited. This is consistent with previous studies in which although the transplanted cells were detectable only at early time points, they show anyway to have a clear positive effect, mainly due to the release of numerous angiogenic factors in the short time frame of their survival (Relative Roles of Direct Regeneration Versus Paracrine Effects of Human Cardiosphere-Derived Cells Transplanted Into Infarcted Mice, Isotta Chimenti, Circulation research 2010).

Biomaterial scaffold architecture is known to significantly influence the implant vascularization. Recently, 3D scaffold simulation models were developed to investigate the impact of various design parameters on implant degradation and vascularization [45]. In particular, Mehdizadeh et al. reported that pores with higher interconnectivity and porosity support rapid and extensive angiogenesis. Therefore, in our study NF hydrogel was generated with either a closed or an open structure to 
investigate the role of interconnected large openings in blood vessel infiltration. The in vivo results showed that superior in vivo infiltration of blood vessels in RR-ELR hydrogels was mainly due to the functionalization and not to the open architecture. Functionalization with both RGD and REDV further supported the overall cell adhesion and in particular of endothelial cells. [29]. Host cell infiltration was also highly promoted in RR-hydrogel, most likely thanks to their superior elastase sensitiveness. In contrast to RGD and REDV gels, NF ELR not only inhibited cell adhesion and interactions (cells were indeed mostly encapsulated as single unit) but also significantly affected the SVF secretion profile, known to be mostly pro-angiogenic [21], steering them towards an anti-angiogenic outcome. Angiogenesis indeed was completely inhibited up to 28 days in vivo within NF hydrogels.

Functionalization also resulted in having an important effect on the infiltration of host inflammatory cells within the implants. Subcutaneous implantation in rats deemed in being a suitable proof-of-concept model to test the vascularization and host interaction, the implants being supportive but not directly inducing angiogenesis. Although nude rats were used to avoid an immune response directed towards the human implanted cells, T-cell-deficient animal models still lead to a normal foreign body response to biomaterials [46, 47]. Although SVF cells were reported to play an important antiinflammatory role in tissue regeneration [22], our findings show how this potential can still be modulated by the functionalization of the hydrogels used to deliver the cells in vivo. Scaffold architecture is also reported to significantly affect the host immune response. In particular, highly porous scaffolds seemed to stimulate less severe immune responses to biomaterials probably because they allowed cell infiltrate and the scaffold digestion [48]. In our study, we found that the open structure and the functionalization allowed an increasing infiltration of host cells with time in vivo and a resorption of the hydrogel without generating a severe foreign body reaction. Although 
NF hydrogels did not degrade and were not colonized by host cells, no inflammatory reaction was observed around the grafts.

Engineered tissues elicit the host immune response upon implantation and the balance between inflammation and pro-resolution is essential to determine their rejection or successful engraftment [48]. Therefore, successful tissue and organ regeneration/repair based on engineered construct approaches highly depends on the vascularization dynamics of the implant and the immune response and both need to be tailored to the specific application (e.g. highly vascularized or avascular tissues, as myocardium and hyaline cartilage, respectively) and to the inflammatory condition of the recipient site. The here proposed strategy needs to be further validated with a larger number of donors in ad hoc immunocompetent animal models to test the different possible applications (e.g. in ischemic heart or articular cartilage defect models). Our study showed how angiogenesis and host integration of the engineered tissues can easily be controlled by modulating the functionalization of the hydrogel alone. The here proposed strategy could be easily implemented and adapted to the specific type of tissue/organ regeneration further progressing towards a successful regenerative medicine.

\section{Acknowledgements}

The authors wish to thank Dr Max Hans-Peter Gay who assisted in the proof-reading of the manuscript, Evi Bieler for the technical assistance with the SEM, and Gabriele Martin for the graphical assistance with figure preparation.

. This study was funded by the Swiss Heart Foundation and the Department of Surgery of the University Hospital Basel. We also acknowledge financial support from the EU through the "THE GRAIL" project (grant 278557), "BIOGEL" project (grant 642687), "ELASTISLET" (grant 646075) and the "ANGIOMAT TRAIN" project (grant 317304), 
from the MINECO (MAT-2010-15982, MAT2010-15310, PRI-PIBAR-2011-1403 and MAT2012-38043-C02-01), the JCyL (projects VA152A12-2, VA244U13 and VA155A12-2), the CIBER-BBN, the JCyL and the Instituto de Salud Carlos III under the "Network Center of Regenerative Medicine and Cellular Therapy of Castilla and Leon". 


\section{References}

[1] Moutos FT, Glass KA, Compton SA, Ross AK, Gersbach CA, Guilak F, Estes BT. Anatomically shaped tissue-engineered cartilage with tunable and inducible anticytokine delivery for biological joint resurfacing. Proc Natl Acad Sci U S A. 2016 Aug 2;113(31):E4513-22. doi: 10.1073/pnas.1601639113. Epub 2016 Jul 18.

[2] Turnbull IC, Karakikes I, Serrao GW, Backeris P, Lee JJ, Xie C, Senyei G, Gordon RE, Li RA, Akar FG, Hajjar RJ, Hulot JS, Costa KD. Advancing functional engineered cardiac tissues toward a preclinical model of human myocardium. FASEB J. 2014 Feb;28(2):644-54. doi: 10.1096/fj.13-228007.

[3] Tondera C, Hauser S, Krüger-Genge A, Jung F, Neffe AT, Lendlein A, Klopfleisch R, Steinbach J, Neuber C, Pietzsch J. Gelatin-based Hydrogel Degradation and Tissue Interaction in vivo: Insights from Multimodal Preclinical Imaging in Immunocompetent Nude Mice. Theranostics. 2016 Sep 12;6(12):2114-2128.

[4] Blinder YJ, Freiman A, Raindel N, Mooney DJ, Levenberg S. Vasculogenic dynamics in 3D engineered tissue constructs. Sci Rep. 2015 Dec 9;5:17840. doi: 10.1038/srep17840.

[5] Shafiq M, Jung Y, Kim SH. Insight on stem cell preconditioning and instructive biomaterials to enhance cell adhesion, retention, and engraftment for tissue repair. Biomaterials. 2016 Jun;90:85-115. doi: 10.1016/j.biomaterials.2016.03.020.

[6] Sun X, Altalhi W, Nunes SS. Vascularization strategies of engineered tissues and their application in cardiac regeneration. Adv Drug Deliv Rev. 2016 Jan 15;96:183-94. doi: 10.1016/j.addr.2015.06.001.

[7] Centola M, Abbruzzese F, Scotti C, Barbero A, Vadalà G, Denaro V, Martin I, Trombetta M, Rainer A, Marsano A. Scaffold-based delivery of a clinically relevant anti- 
angiogenic drug promotes the formation of in vivo stable cartilage. Tissue Eng Part A. 2013 Sep;19(17-18):1960-71. doi: 10.1089/ten.TEA.2012.0455.

[8] Jun Yoshioka, MD, PhD and Richard T. Lee, MD. Vascularization as a Potential Enemy in Valvular Heart Disease. Circulation. 2008 October 21; 118(17): 1694-1696. doi:10.1161/CIRCULATIONAHA.108.809475.

[9] Mehdizadeh H, Bayrak ES, Lu C, Somo SI, Akar B, Brey EM, Cinar A. Agent-based modeling of porous scaffold degradation and vascularization: Optimal scaffold design based on architecture and degradation dynamics. Acta Biomater. 2015 Nov;27:16778. doi: 10.1016/j.actbio.2015.09.011. Epub 2015 Sep 9

[10] Lovett M, Lee K, Edwards A, Kaplan DL. Vascularization strategies for tissue engineering. Tissue Eng Part B Rev. 2009 Sep;15(3):353-70. doi: 10.1089/ten.TEB.2009.0085.

[11] Lakshmanan R, Kumaraswamy P, Krishnan UM, Sethuraman S.Engineering a growth factor embedded nanofiber matrix niche to promote vascularization for functional cardiac regeneration. Biomaterials. 2016 Aug;97:176-95.

[12] Kharraz Y, Guerra J, Mann CJ, Serrano AL, Muñoz-Cánoves P. Macrophage plasticity and the role of inflammation in skeletal muscle repair. Mediators Inflamm. 2013;2013:491497. doi: 10.1155/2013/491497.

[13] Ma S, Xie N, Li W, Yuan B, Shi Y, Wang Y. Immunobiology of mesenchymal stem cells. Cell Death Differ. 2014 Feb;21(2):216-25. doi: 10.1038/cdd.2013.158.

[14] Sensebé L, Krampera M, Schrezenmeier H, Bourin P, Giordano R. Mesenchymal stem cells for clinical application. Vox Sang. 2010 Feb;98(2):93-107. doi: 10.1111/j.1423-0410.2009.01227. Review.

[15] Prasongchean W, Ferretti P.N. Autologous stem cells for personalised medicine. Biotechnol. 2012 Sep 15;29(6):641-50. doi: 10.1016/j.nbt.2012.04.002. 
[16] Prockop DJ. Marrow stromal cells as stem cells for nonhematopoietic tissues. Science. 1997 Apr 4;276(5309):71-4.

[17] Pittenger MF, Mackay AM, Beck SC, Jaiswal RK, Douglas R, Mosca JD, Moorman MA, Simonetti DW, Craig S, Marshak DR. Multilineage potential of adult human mesenchymal stem cells. Science. 1999 Apr 2;284(5411):143-7.

[18] Zuk PA, Zhu M, Mizuno H, Huang J, Futrell JW, Katz AJ, Benhaim P, Lorenz HP, Hedrick MH. Multilineage cells from human adipose tissue: implications for cell-based therapies. Tissue Eng. 2001 Apr;7(2):211-28.

[19] Caplan Al. Adult mesenchymal stem cells for tissue engineering versus regenerative medicine. J Cell Physiol. 2007 Nov;213(2):341-7.

[20] Guo J, Nguyen A, Banyard DA, Fadavi D, Toranto JD, Wirth GA, Paydar KZ, Evans GR, Widgerow AD. Stromal vascular fraction: A regenerative reality? Part 2: Mechanisms of regenerative action. J Plast Reconstr Aesthet Surg. 2016 Feb;69(2):180-8. doi: 10.1016/j.bjps.2015.10.014.

[21] Rehman J, Traktuev D, Li J, Merfeld-Clauss S, Temm-Grove CJ, Bovenkerk JE, Pell $\mathrm{CL}$, Johnstone $\mathrm{BH}$, Considine RV, March $\mathrm{KL}$. Secretion of angiogenic and antiapoptotic factors by human adipose stromal cells. Circulation. 2004 Mar $16 ; 109(10): 1292-8$.

[22] Premaratne GU, Ma LP, Fujita M, Lin X, Bollano E, Fu M. Stromal vascular fraction transplantation as an alternative therapy for ischemic heart failure: anti-inflammatory role. J Cardiothorac Surg. 2011 Mar 31;6:43. doi: 10.1186/1749-8090-6-43.

[23] Gonzalez de Torre I, Santos M, Quintanilla L, Testera A, Alonso M, Rodríguez Cabello JC. Elastin-like recombinamer catalyst-free click gels: characterization of poroelastic and intrinsic viscoelastic properties. Acta Biomater. 2014 Jun;10(6):2495505. doi: 10.1016/j.actbio.2014.02.006. 
[24] Testera AM, Girotti A, Gonzalez de Torre I, Quintanilla L, Santos M, Alonso M, Rodríguez-Cabello JC. Biocompatible elastin-like click gels: design, synthesis and characterization. J Mater Sci Mater Med. 2015 Feb;26(2):105. doi: 10.1007/s10856015-5435-1.

[25] Patel A, Fine B, Sandig M, Mequanint K. Elastin biosynthesis: The missing link in tissue-engineered blood vessels. Cardiovasc Res. 2006 Jul 1;71(1):40-9. Epub 2006 Feb 28. doi: 10.1016/j.cardiores.2006.02.021.

[26] Wendt D, Marsano A, Jakob M, Heberer M, Martin I. Oscillating perfusion of cell suspensions through three-dimensional scaffolds enhances cell seeding efficiency and uniformity. Biotechnol Bioeng. 2003 Oct 20;84(2):205-14.

[27] Güven S, Mehrkens A, Saxer F, Schaefer DJ, Martinetti R, Martin I, Scherberich A. Engineering of large osteogenic grafts with rapid engraftment capacity using mesenchymal and endothelial progenitors from human adipose tissue. Biomaterials. 2011 Sep;32(25):5801-9. doi: 10.1016/j.biomaterials.2011.04.064.

[28] Rodriguez-Cabello JC, Pierna M, Fernandez-Colino A, Garcia-Arevalo C, Arias FJ. Recombinamers: combining molecular complexity with diverse bioactivities for advanced biomedical and biotechnological applications. Adv Biochem Eng Biotechnol 2011;125:145-79.

[29] Gonzalez de Torre I, Wolf F, Santos M, Rongen L, Alonso M, Jockenhoevel S, Rodríguez-Cabello JC, Mela P. Elastin-like recombinamer-covered stents: Towards a fully biocompatible and non-thrombogenic device for cardiovascular diseases. Acta Biomater. 2015 Jan;12:146-55. doi: 10.1016/j.actbio.2014.10.029.

[30] Cerino G, Gaudiello E, Grussenmeyer T, Melly L, Massai D, Banfi A, Martin I, Eckstein F, Grapow M, Marsano A. Three dimensional multi-cellular muscle-like tissue engineering in perfusion-based bioreactors. Biotechnol Bioeng. 2016 Jan;113(1):22636. doi: 10.1002/bit.25688. 
[31] Corselli M, Crisan M, Murray IR, West CC, Scholes J, Codrea F, Khan N, Péault

B. Identification of perivascular mesenchymal stromal/stem cells by flow cytometry. Cytometry A. 2013; 83(8): 714-20.

[32] Franklin SL, Ferry RJ Jr, Cohen P. Rapid insulin-like growth factor (IGF)independent effects of IGF binding protein-3 on endothelial cell survival. J Clin Endocrinol Metab. 2003 Feb;88(2):900-7.

[33] Muralidhar K, Lee J. Prolactin and Angiogenesis: Biological Implications of Microheterogeneity. Kambadur Muralidhar and Jaeok Lee (2013). Prolactin and Angiogenesis: Biological Implications of Microheterogeneity, Prolactin, Prof. György M. Nagy (Ed.), InTech, DOI: 10.5772/54318. Available from: http://www.intechopen.com/books/prolactin/prolactin-and-angiogenesis-biologicalimplications-of-microheterogeneity.

[34] Tarui T, Majumdar M, Miles LA, Ruf W, Takada Y.Plasmin-induced migration of endothelial cells. A potential target for the anti-angiogenic action of angiostatin. J Biol Chem. 2002 Sep 13;277(37):33564-70.

[35] Shimizu K, Watanabe K, Yamashita H, Abe M, Yoshimatsu H, Ohta H, Sonoda H, Sato Y.Gene regulation of a novel angiogenesis inhibitor, vasohibin, in endothelial cells Biochem Biophys Res Commun. 2005 Feb 18;327(3):700-6

[36] Shi J, Wei PK. Interleukin-8: A potent promoter of angiogenesis in gastric cancer. Oncol Lett. 2016 Feb;11(2):1043-1050. Epub 2015 Dec 15.

[37] Niu J, Azfer A, Zhelyabovska O, Fatma S, Kolattukudy PE. Monocyte chemotactic protein (MCP)-1 promotes angiogenesis via a novel transcription factor, MCP-1induced protein (MCPIP). J Biol Chem. 2008 May 23;283(21):14542-51. doi: 10.1074/jbc.M802139200. Epub 2008 Mar 24.

[38] Azar WJ, Azar SH, Higgins S, Hu JF, Hoffman AR, Newgreen DF, Werther GA, Russo VC. IGFBP-2 enhances VEGF gene promoter activity and consequent 
promotion of angiogenesis by neuroblastoma cells. Endocrinology. 2011 Sep;152(9):3332-42. doi: 10.1210/en.2011-1121. Epub 2011 Jul 12.

[39] Taylor SR, Markesbery MG, Harding PA. Heparin-binding epidermal growth factorlike growth factor (HB-EGF) and proteolytic processing by a disintegrin and metalloproteinases (ADAM): a regulator of several pathways. Semin Cell Dev Biol. 2014 Apr;28:22-30. doi: 10.1016/j.semcdb.2014.03.004. Epub 2014 Mar 25.

[40] Ferrara N. Vascular endothelial growth factor. Arterioscler Thromb Vasc Biol. 2009 Jun;29(6):789-91. doi: 10.1161/ATVBAHA.108.179663. Epub 2009 Jan 22.

[41] Salven P, Hattori K, Heissig B, Rafii S. Interleukin-1alpha promotes angiogenesis in vivo via VEGFR-2 pathway by inducing inflammatory cell VEGF synthesis and secretion. FASEB J. 2002 Sep;16(11):1471-3. Epub 2002 Jul 18.

[42] Breuss JM, Uhrin P. VEGF-initiated angiogenesis and the uPA/uPAR system. Cell Adh Migr. 2012 Nov 1; 6(6): 535-540. doi: 10.4161/cam.22243.

[43] Hubbell JA, Massia SP, Desai NP, Drumheller PD. Endothelial cell-selective materials for tissue engineering in the vascular graft via a new receptor. Biotechnology (NY). 1991 Jun;9(6):568-72.

[44] Akthar S, Patel DF, Beale RC, Peiró T, Xu X, Gaggar A, Jackson PL, Blalock JE, Lloyd CM, Snelgrove RJ. Matrikines are key regulators in modulating the amplitude of lung inflammation in acute pulmonary infection. Nat Commun. 2015 Sep 24;6:8423. doi: $10.1038 /$ ncomms 9423 .

[45] Mehdizadeh H, Sumo S, Bayrak ES, Brey EM, Cinar A.Three-dimensional modeling of angiogenesis in porous biomaterial scaffolds. Biomaterials. 2013 Apr;34(12):2875-87. doi: 10.1016/j.biomaterials.2012.12.047. Epub 2013 Jan 26.

[46] Rodríguez-Lorenzo LM, Carrodeguas RG, Rodríguez MA, De Aza S, Parra J, Román JS. Development of wollastonite-poly(ethylmethacrylate co-vinylpyrrolidone) 
based materials for multifunctional devices. J Biomed Mater Res A. 2007 Jun $1 ; 81(3): 603-10$.

[47] Rodriguez A, MacEwan SR, Meyerson H, Kirk JT, Anderson JM. The Foreign Body Reaction in T cell deficient mice. J Biomed Mater Res A. 2009 July ; 90(1): . doi:10.1002/jbm.a.32050.

[48] Crupi A, Costa A, Tarnok A, Melzer S, Teodori L. Inflammation in tissue engineering: The Janus between engraftment and rejection. European Journal of Immunology 2015 Dec;45(12):3222-36. doi: 10.1002/eji.201545818. 